\title{
Estudio clínico y epidemiológico de las neumonías por Mycoplasma pneumoniae y adenovirus en un hospital de Barcelona
}

S. Ortigosa Gómez ${ }^{\mathrm{a}}$, L. Ymbert-Pellejáa ${ }^{\mathrm{a}}$ RM. Busquets-Monge ${ }^{\mathrm{a}}$, M. Álvaro-Lozanoa, A. González-Cuevas ${ }^{b}$, A. Martínez-Roiga

aServicio de Pediatría. Hospital del Mar. Barcelona. España. bLaboratori de Referencia de Catalunya. El Prat de Llobregat. Barcelona. España.

\section{Resumen}

Introducción: Mycoplasma pneumoniae y adenovirus son dos de las causas más frecuentes de neumonía en la infancia. El objetivo del estudio es describir las características epidemiológicas, clínicas, radiológicas y analíticas de los casos de neumonía por dichos microorganismos en menores de 15 años en un hospital de Barcelona. Determinar si existen diferencias entre etiologías y edades y conocer los casos de coinfección.

Material y métodos: estudio retrospectivo, mediante revisión de las historias clínicas de los menores de 15 años atendidos en el periodo 2000-2007 en el hospital y cuya lgM para M. pneumoniae $y / o$ adenovirus fue positiva o se obtuvo inmunofluorescencia o cultivo positivo para adenovirus. Posteriormente se realizó un análisis estadistico mediante SPSS ${ }^{\circledR}$.

Resultados: se diagnosticaron 153 neumonías: 73 por M. pneumoniae y 80 por adenovirus. La media de edad fue de 5,7 y 3,5 años respectivamente, siendo el 46\% menores de 5 años en la neumonía por M. pneumoniae y el 71,3\% por adenovirus. No se observó predominio estacional claro. Las manifestaciones clínicas más frecuentes fueron fiebre y tos, con buen estado general. La auscultación pulmonar fue patológica en 141 casos, predominando la unilateralidad y crepitantes. La alteración radiológica fue mayoritariamente unilateral. Los resultados analíticos no fueron significativos. Se encontraron 23 coinfecciones entre ambos y 22 con otros microorganismos.

Conclusiones: M. pneumoniae y adenovirus deben ser considerados como agentes causales de neumonías en cualquier edad de la infancia. Destaca la dificultad para establecer empíricamente el diagnóstico etiológico, la similitud clínica entre mayores y menores de 5 años y el porcentaje de coinfecciones.

Palabras clave: Adenovirus. Mycoplasma pneumoniae. Neumonía. Niño.

Clinical and epidemiological study of Mycoplasma pneumoniae and adenoviral pneumonia in a hospital of Barcelona

Abstract

Introduction: Mycoplasma pneumoniae and adenovirus are two of the main causes of pneumonia in children. The objectives of the study are to describe the epidemiological, clini- 
cal, radiological and laboratory characteristics of the cases of pneumonia caused by these microorganisms in children younger than 15 years in a Hospital of Barcelona. And also to know if there are differences between both etiologies, between children with different ages and to know the cases of coinfections.

Methods: retrospective study of review of clinical histories of children under 15 who were visited from 2000 to 2007 in the hospital and whose IgM against M. pneumonia and/or adenovirus or the immunofluorescence or culture for adenovirus had been positive. A statistical study with the program SPSS was performed.

Results: seventy-three pneumonias caused by M. pneumoniae and 80 by adenovirus were diagnosed. Thirty-five were girls and 28 boys. The mean age was 5.7 and 3.5 years respectively; $46.6 \%$ were younger than 5 years in M. pneumoniae and $71.3 \%$ in adenovirus infections. There was no clear stational prevalence. The most frequent clinical manifestations were fever and cough, with good general aspect. The auscultatory findings were pathological in 141 cases, being crepitations and unilateral affectation the most frequent features. Chest $x$-rays showed predominantly unilateral affectation. Blood tests did not show significative alterations. There were 23 coinfections found with both microorganism and 22 with others.

Conclusions: M. pneumoniae and adenovirus should be considered causal agents of paediatric pneumonias. Is remarkable the difficulty in the differential diagnosis with other pneumonias, the clinical similitude between younger and older than 5 years and the important percentage of coinfections.

Key words: Adenovirus. Pneumonia. Child. Mycoplasma pneumoniae.

\section{Introducción}

Mycoplasma pneumoniae y adenovirus producen un importante porcentaje de las infecciones respiratorias durante la infancia ${ }^{1-4}$.

El M. pneumoniae es un microorganismo pleomórfico deficiente en pared celular, que infecta el tracto respiratorio en su forma filamentosa, con adherencia a las células epiteliales y con producción de productos citotóxicos ${ }^{1,2}$.

La infección tiene una incidencia mundial entre $60-100$ casos/1.000 habitantes, con gran variabilidad de unas regiones a otras ${ }^{1,2,5}$. Representa el 7$25 \%$ de las neumonías diagnosticadas en la infancia ${ }^{6-11}$. Es una de las causas más frecuentes de neumonía comunitaria en mayores de 5 años s.5-7, $^{2,12}$ y cada vez más en menores de dicha edad ${ }^{5}$ 7,13,14. Tiene un patrón endémico sin predominio estacional $\left.\right|^{1-2,7,15}$, aunque hay estudios en los que observan mayor prevalencia entre los meses de mayo y juli $^{5,6,9,13}$ y en otros un cierto predominio en los meses de otoño ${ }^{15,16} \mathrm{e}$ invier$\mathrm{no}^{6}$, sobre todo durante las epidemias. Se describen brotes epidémicos en ciclos entre 2 y 7 años, en los cuales su incidencia aumenta 3-5 veces y donde parece haber una evolución más tórpi$\mathrm{da}^{2,5,6,6,10,14}$.

Su localización es principalmente respiratoria, puede afectar tanto al tracto 
respiratorio superior, como inferior ${ }^{10,14}$. Aunque generalmente presenta una evolución benigna y autolimitada ${ }^{6,12,17}$, de manera ocasional se han descrito complicaciones, como derrame pleural (20\% de los casos), neumatoceles, abscesos o necrosis, bronquiolitis obliterante, bronquiectasias, neumotórax, fibrosis intersticial crónica y síndrome de distrés respiratorio ${ }^{1,6,12,14,16}$. Existen afectaciones extrarrespiratorias, pero son poco frecuentes en la infancia $a^{9,10,12,16}$.

Hasta hace poco se consideraba diferente la presentación clínica según la edad superior o inferior a 5 años: los menores, con tendencia a ser asintomáticos o presentar leves manifestaciones de las vías respiratorias superiores, mientras que en los mayores predominaría el proceso neumónico ${ }^{2,59,12}$.

El adenovirus es un virus ADN, que pertenece a la familia Adenoviridae. Presenta un período de incubación entre 4 y 10 días. Se propaga por vía aérea, fecaloral o por contacto, con especial predilección por las células epiteliales, afectando a casi todas las mucosas 3 3,18-20.

Causa el $5-8 \%$ de las enfermedades respiratorias agudas en el lactante ${ }^{3,4}$ y el $5-24 \%$ en los menores de 5 años $^{19-22}$. Es responsable del $10-20 \%$ de las neumonías en la infancia ${ }^{18,19}$. Suele ser más frecuente en menores de 5 años, con una incidencia que disminuye con la edad y presenta mayor gravedad cuanto menor es la edad ${ }^{3,18,19,22}$.

Es una infección endémica en todo el mundo y en todas las épocas, produce brotes más frecuentes en primavera y verano ${ }^{3,4}$, aunque algunos casos se describen más durante el primer cuatrimestre del año y otoño-invierno ${ }^{19}$.

Provoca gran variedad de procesos clínicos, muchos asintomáticos y ocasionalmente enfermedad grave ${ }^{19-21}$. Las manifestaciones más frecuentes son respiratorias (tanto de vías altas como bajas) y gastrointestinales ${ }^{19,22-24}$.

En general son cuadros respiratorios benignos y autolimitados y las principales manifestaciones clínicas son fiebre, rinitis y tos. Aunque un 30\% presenta manifestaciones sistémicas ${ }^{19}$.

El $14-20 \%$ de las neumonías por adenovirus puede dejar secuelas, desde una leve alteración de la función pulmonar a bronquiectasias, bronquiolitis obliterante, o cuadros asmáticos posteriores ${ }^{20-25}$.

El diagnóstico etiológico vendrá dado por el aislamiento en cultivo, la demostración de antígenos, la reacción en cadena de la polimerasa (RCP) o la serología ${ }^{3,14,26-28}$. Diagnóstico que suele tardar y obliga en la mayoría de casos a iniciar un tratamiento empírico ante una neumonía. 
Las coinfecciones son frecuentes en la infancia. Se estima que entre el 10 $25 \%$ de los casos de neumonía en esta edad están causadas por más de un agente etiológico ${ }^{7}$. M. pneumoniae y adenovirus actúan con frecuencia como copatógenos con otros agentes infecciosos (30-50\% de los casos): C. pneumoniae, S. pneumoniae, B. pertussis u otros virus respiratorios ${ }^{7,14}$.

El objetivo del trabajo fue estudiar lasneumonías causadas por M. pneumoniae y adenovirus en el Servicio de Pediatría de un hospital general de Barcelona, para conocer las características epidemiológicas, clínicas, radiológicas y analíticas; comparar las características clínicas entre ambas y por edades (menores y mayores de 5 años) y conocer los casos en que se confirmó coinfección entre varios agentes etiológicos.

\section{Material y métodos}

Estudio retrospectivo de las historias clínicas de los menores de 15 años atendidos por neumonía en el Servicio de Pediatría del Hospital del Mar de Barcelona entre los años 2000-2007 y que presentaron un valor positivo de IgM para $M$. pneumoniae o adenovirus o cultivo positivo para adenovirus en la fase aguda de la enfermedad.
Todos los pacientes pediátricos atendidos en urgencias diagnosticados de neumonía son ingresados, ya que su diagnóstico se considera criterio de ingreso en nuestro hospital. Se realizó hemocultivo y serologías (técnica de enzimainmunoensayo) para M. pneumoniae (ELISA), adenovirus (EIA) y Chlamydia pneumoniae (ELISA) y en algún caso además, inmunofluorescencia indirecta y cultivo de secreciones nasofaríngeas para adenovirus. En los casos con un cultivo o inmunofluorescencia positiva para adenovirus, IgM positiva para M. pneumoniae o adenovirus, se estudió las variables: época del año, edad, sexo, antecedentes, presentación clínica y días de evolución, características de la auscultación, aspectos radiológicos y analíticos, tratamiento administrado y si existía coinfección con algún otro agente. Éste último dato no fue posible en todos los casos, ya que aparte de los estudios citados, el resto de pruebas para posibles etiologías no se hacían sistemáticamente. Se consideró como posible coinfección la existencia de IgM positiva, el aislamiento del virus en secreciones respiratorias o el cultivo positivo de algún virus.

Estos datos se registraron en una hoja de cálculo $\left(\right.$ Excel $^{\circledR}$ 2003) y se realizó el análisis estadístico. Las variables cua- 
litativas se describen con su frecuencia absoluta y su porcentaje. Las variables cuantitativas con su media y desviación estándar o con su mediana y cuartiles 1 y 3 en el caso de no ajustarse a una distribución normal. En los contrastes entre variables cualitativas se utilizó la prueba de $\chi^{2}$ o la exacta de Fisher en función de las condiciones de aplicación. En los contrastes para variables cuantitativas se utilizó la prueba $U$ de Mann-Whitney. El nivel de significación utilizado en todos los contrastes fue $\alpha \leq 0,05$. El análisis se realizó con el paquete estadístico SPSS ${ }^{\oplus}$ para Windows ${ }^{\circledast}$ versión 12.0.

\section{Resultados}

\section{Epidemiología}

Durante los años 2000-2007 se diagnosticaron en el Servicio de Pediatría del Hospital del Mar de Barcelona 652 neumonías, de ellas: 73 con IgM positiva para $M$. pneumoniae $(11,2 \%), 80$ para adenovirus $(12,2 \%)$ y en 23 existió coinfección de ambos (3,5\%).

En la distribución anual (figura 1) destaca el elevado número de casos por $M$. pneumoniae en 2002 y de ambas etiologías en 2004. No se observa un claro predominio estacional. La neumonía por M. pneumoniae disminuye en

Figura 1. Distribución de las neumonías según la etiología en los diferentes años.

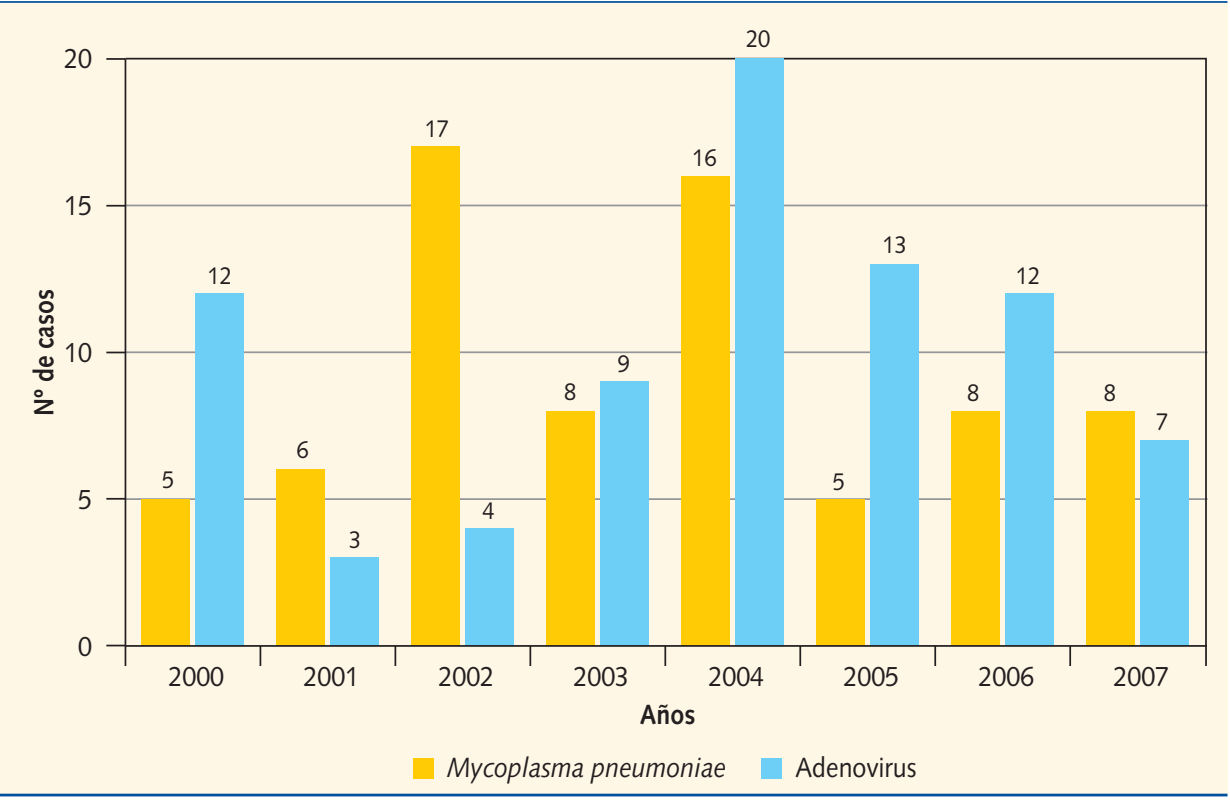


agosto y septiembre y el adenovirus predomina al final del invierno y en primavera (figura 2).

No se aprecian diferencias por sexo, aunque hay una incidencia discretamente superior en niñas en ambas etiologías (40/73 casos en M. pneumoniae y 42/80 en adenovirus).

La edad osciló entre 2 meses y 14 años con una edad media de 5,7 años para M. pneumoniae y de 3,5 años para adenovirus. La edad de presentación más frecuente fue 4 años en $M$. pneumoniae y 2 en adenovirus (figura 3 ). Un 46,6\% (34 casos) eran menores de 5 años en la neumonía por $M$. pneumo- niae y un $71,3 \%$ (57 casos) por adenovirus.

\section{Manifestaciones clínicas}

La mayoría $(75,8 \%)$ cursaron con buen estado general. El promedio de días de enfermedad previos al diagnóstico fue de 8,7. Más de las dos terceras partes $(69,3 \%)$ tuvieron una evolución menor de una semana hasta el diagnóstico: 22 casos (13 M. pneumoniae, 5 adenovirus y 4 con coinfección) menos de 48 horas.

Más del $90 \%$ había presentado fiebre, con una media de 4 días. La tos estuvo presente en más del $87 \%$, sin po-

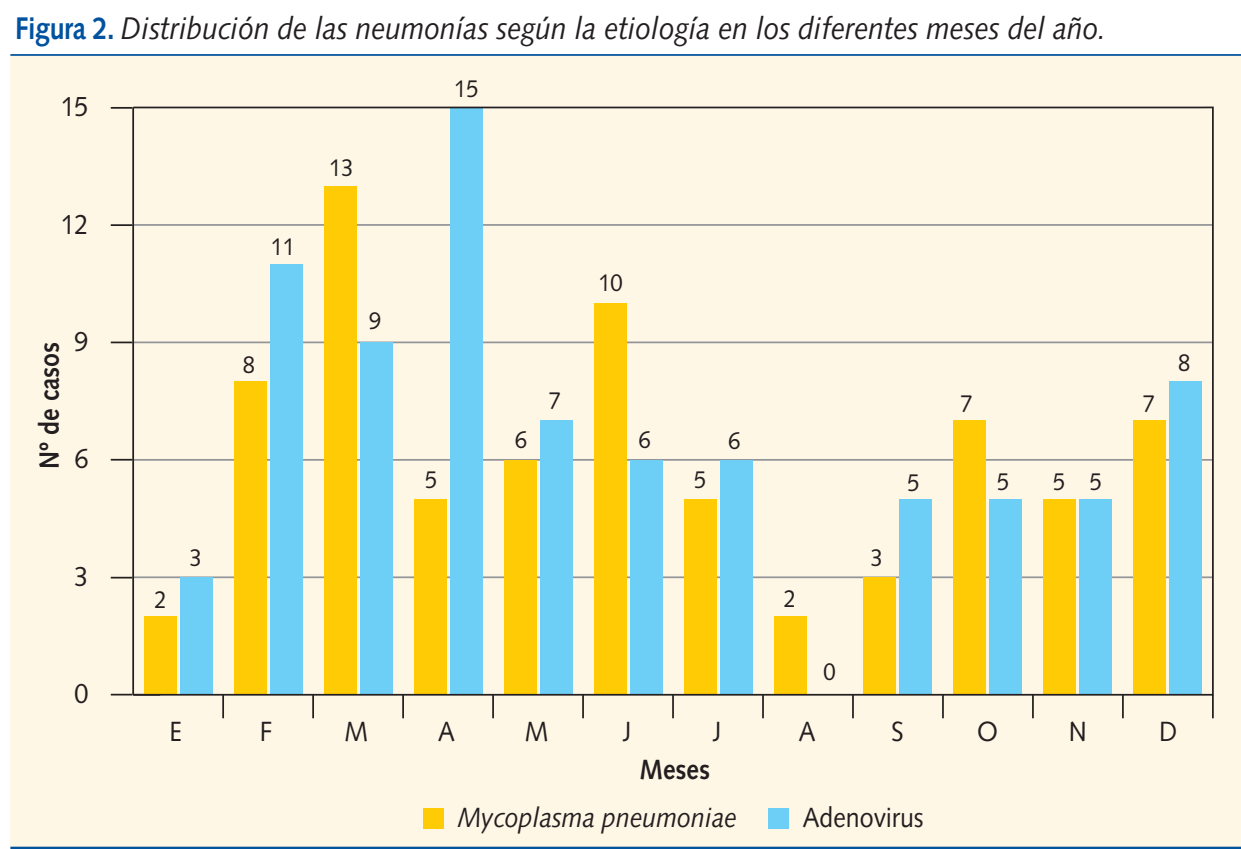


der especificar el tipo al ser un estudio retrospectivo y no recoger los datos con el mismo patrón anamnésico.

Otras manifestaciones del tracto respiratorio eran: faringitis $(26 / 21,3 \%)$, dolor torácico $(9,6 / 3,8 \%)$, otitis $(11 / 12,5 \%)$ y dificultad respiratoria $(9,6 / 27,5 \%)$, sobre todo en los casos de adenovirus. Las manifestaciones extrarrespiratorias en 53 pacientes fueron: vómitos $(19,2 / 11,3 \%)$, anorexia $(9,6 / 12,5 \%)$, diarrea $(9,6 / 12,5 \%)$, dolor abdominal $(6,8 / 8,8 \%)$ y cefalea $(4,1 / 3,8 \%)$. Además 7 pacientes tuvieron manifestaciones cutáneas. Los datos mencionados corresponden al con- junto de casos de ambas etiologías; en la figura 4 pueden verse desglosados por etiologías.

La semiología respiratoria fue muy variable: 32 casos $(15,1 \%$ M. pneumoniae y $32,5 \%$ adenovirus) con auscultación bilateral patológica, 89 (76,7\% y $60 \%$ respectivamente) con auscultación patológica unilateral, (existió discreto predominio en el hemitórax izquierdo en el caso de M. pneumoniae [33 casos frente a 23 en el hemitórax derecho]) y 9 ( $8,2 \%$ de $M$. pneumoniae y $7,5 \%$ de adenovirus) con auscultación normal. El signo auscultatorio más frecuente fue los crepitantes (49,3\% en M. pneumo-

Figura 3. Distribución de las neumonías según la etiología por edades.

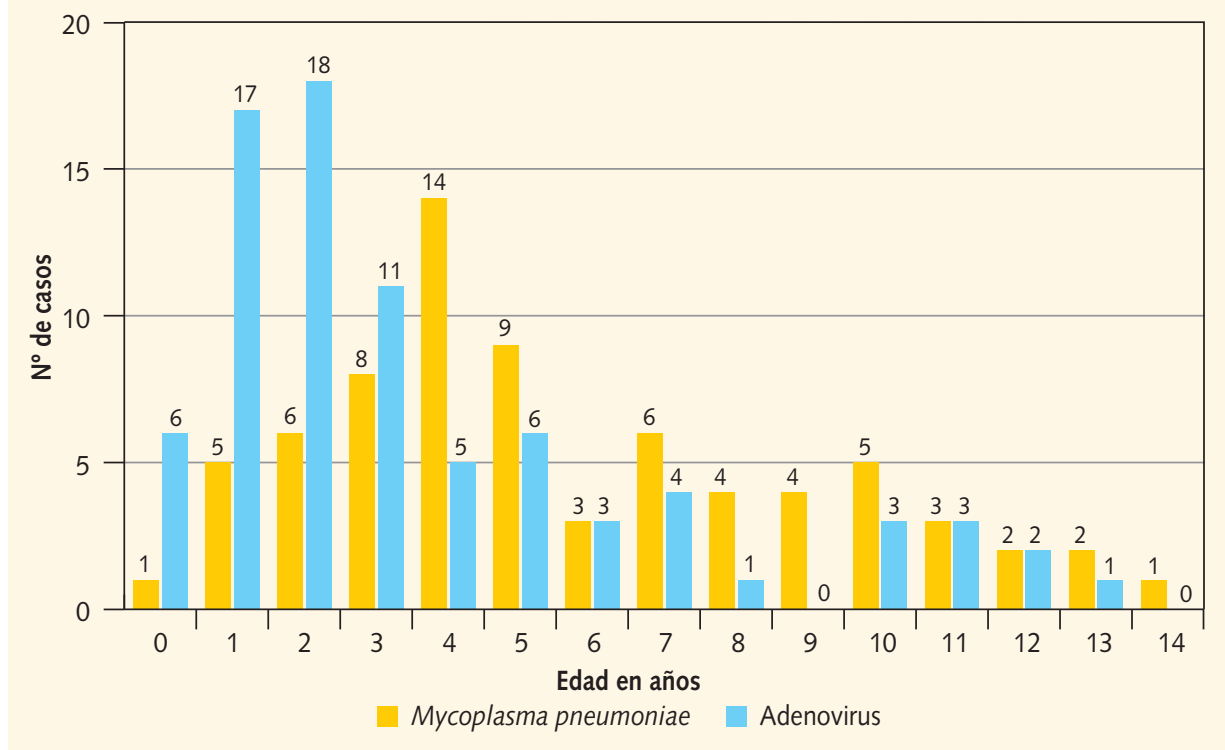


niae y $47,5 \%$ en adenovirus), seguido de hipofonesis (hipoventilación) (38,4\% en M. pneumoniae y $25 \%$ en adenovirus). Destaca en el adenovirus la presencia de roncus y subcrepitantes en el $18,8 \%$ de los casos, frente a un $6,8 \%$ y un $13,7 \%$ respectivamente en el M. pneumoniae. En algunos hubo sibilancias $(5,5 \%$ en $M$. pneumoniae y $13,8 \%$ en adenovirus) y en 3 soplo tubárico $(4,1 \%$ de los casos de $M$. pneumoniae y $2,5 \%$ de adenovirus).

\section{Radiología}

La mayoría ( $82,2 \%$ en M. pneumoniae y $78,8 \%$ en adenovirus) tenía afectación unilateral. En un $20 \%$ era bilateral, y 10 casos presentaron derrame pleural, más frecuente en $M$. pneumoniae sin diferencia estadísticamente significativa ( $11 \%$ frente a un $3,8 \%$ ).

\section{Laboratorio}

La proteína $C$ reactiva (PCR) media fue de $9,3 \mathrm{mg} / \mathrm{dl}$ en $M$. pneumoniae y $9,5 \mathrm{mg} / \mathrm{dl}$ en adenovirus (rango entre 0,3 y $39,8 \mathrm{mg} / \mathrm{dl}$ ), predominando los valores inferiores a $10 \mathrm{mg} / \mathrm{dl}$. Sólo 19 determinaciones fueron superiores a 20 $\mathrm{mg} / \mathrm{dl}$.

La leucocitosis $\left(>12.000 / \mathrm{mm}^{3}\right)$ fue frecuente, con una media de 17.336

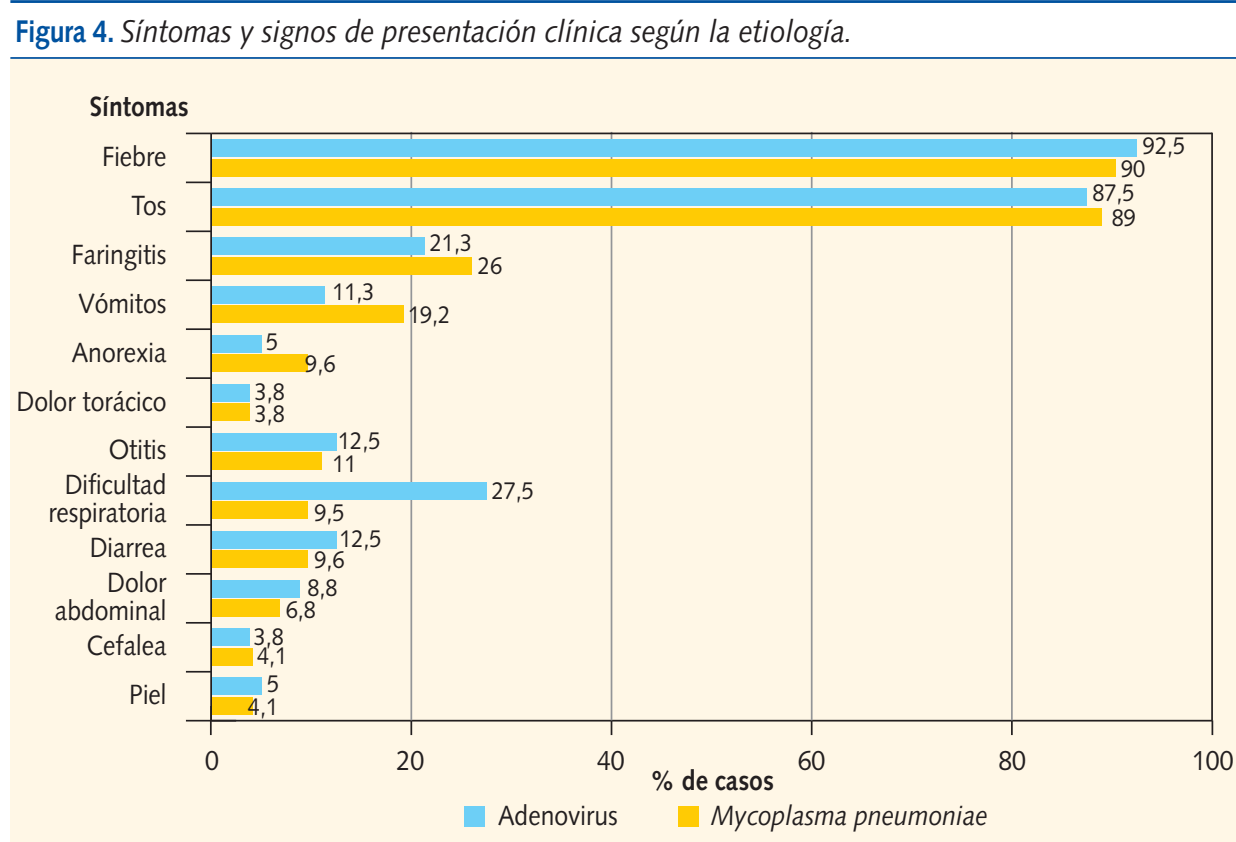


leucocitos en M. pneumoniae y de 17.280 en adenovirus en el momento del diagnóstico, con un valor máximo de 46.500. En la mayoría (67,3\%) existía desviación a la izquierda (> 65\%), con un recuento medio de neutrófilos del $70,1 \%$ en M. pneumoniae y del
$67,2 \%$ en adenovirus, con un rango entre 25,6 y $90,1 \%$.

\section{Tratamiento}

En 63 casos se prescribió betalactámi$\cos$ (43 penicilina y el resto: amoxicilina, amoxicilina-clavulánico, cefotaxima o

Tabla 1. Análisis estadístico de los síntomas y signos clínicos, radiológicos y de laboratorio en las neumonías por Mycoplasma pneumoniae y adenovirus

\begin{tabular}{|c|c|c|c|}
\hline & $\begin{array}{l}\text { Mycoplasma pneumoniae } \\
\mathrm{N}=73(\%)\end{array}$ & $\begin{array}{l}\text { Adenovirus } \\
\mathrm{N}=80(\%)\end{array}$ & $p$ \\
\hline Fiebre & $66(90,4)$ & $74(92,5)$ & $<0,001$ \\
\hline Tos & 65 (89) & $70(87,5)$ & NS \\
\hline Faringitis & $19(26)$ & $17(21,3)$ & NS \\
\hline Dolor abdominal & $5(6,8)$ & $7(8,8)$ & NS \\
\hline Dolor torácico & $7(9,6)$ & $3(3,8)$ & NS \\
\hline Cefalea & $3(4,1)$ & $3(3,8)$ & NS \\
\hline Vómitos & $14(19,2)$ & $9(11,3)$ & NS \\
\hline Otitis & $8(11)$ & $10(12,5)$ & NS \\
\hline Afectación cutánea & $3(4,1)$ & $4(5)$ & NS \\
\hline Dificultad respiratoria & $7(9,6)$ & $22(27,5)$ & 0,005 \\
\hline Diarrea & $7(9,6)$ & $10(12,5)$ & NS \\
\hline Anorexia & $7(9,6)$ & $4(5)$ & NS \\
\hline AP patológica unilateral & $56(76,7)$ & $48(60)$ & NS \\
\hline AP patológica bilateral & $11(15,1)$ & $26(32,5)$ & 0,012 \\
\hline AP normal & $6(8,2)$ & $6(7,5)$ & NS \\
\hline Hipofonesis & $28(38,4)$ & $20(25)$ & 0,054 \\
\hline Crepitantes & $36(49,3)$ & $38(47,5)$ & NS \\
\hline Soplo tubárico & $3(4,1)$ & $2(2,5)$ & NS \\
\hline Roncus & $5(6,8)$ & $15(18,8)$ & 0,029 \\
\hline Subcrepitantes & $10(13,7)$ & $15(18,8)$ & NS \\
\hline Sibilantes & $4(5,5)$ & $11(13,8)$ & NS \\
\hline Rx patológica unilateral & $60(82,2)$ & $63(78,8)$ & NS \\
\hline Rx patológica bilateral & $13(17,8)$ & $17(21,3)$ & NS \\
\hline Derrame pleural & $8(11)$ & $3(3,8)$ & NS \\
\hline Adenovirus/Mycoplasma & $23(31,5)$ & $23(28,8)$ & NS \\
\hline Chlamydia & $11(15,1)$ & $15(18,8)$ & NS \\
\hline $\mathrm{PCR}>15 \mathrm{mg} / \mathrm{dl}$ & $19(26)$ & $17(21,5)$ & NS \\
\hline Leucocitos $>15.000 / \mathrm{mm}^{3}$ & $41(56,2)$ & $46(57,5)$ & NS \\
\hline Neutrófilos $>60 \%$ & $61(83,5)$ & $61(77,2)$ & 0,044 \\
\hline
\end{tabular}


ceftriaxona) durante 7-10 días. En 2 se cambió a macrólidos. En 39 casos fueron tratados con macrólidos: la mayoría (24) con azitromicina 5 días, el resto con claritromicina, salvo un caso con eritromicina. Destacar 28 casos cuyo tratamiento únicamente fue sintomático.

\section{Coinfecciones}

En 23 casos se produjo coinfección entre ambos microorganismos ( $M$. pneumoniae, adenovirus). El resto de coinfecciones se deben considerar hallazgos de un estudio no sistemático (como se comentó en el apartado de

Tabla 2. Análisis estadístico de los síntomas y signos clínicos, radiológicos y de laboratorio entre neumonías en menores y mayores de 5 años

\begin{tabular}{|c|c|c|c|c|c|c|}
\hline & \multicolumn{2}{|c|}{ Mycoplasma pneumoniae } & \multirow[b]{2}{*}{$\mathrm{p}$} & \multicolumn{2}{|c|}{ Adenovirus } & \multirow[b]{2}{*}{$\mathrm{p}$} \\
\hline & $\begin{array}{c}<5 \text { años } \\
N=34(\%)\end{array}$ & $\begin{array}{c}\geq 5 \text { años } \\
N=39(\%)\end{array}$ & & $\begin{array}{c}<5 \text { años } \\
N=57(\%)\end{array}$ & $\begin{array}{c}\geq 5 \text { años } \\
N=23(\%)\end{array}$ & \\
\hline Fiebre & $32(94,1)$ & $34(87,2)$ & 0,04 & $52(91,2)$ & $22(95,7)$ & 0,035 \\
\hline Tos & $30(88,2)$ & $35(89,7)$ & NS & $53(93)$ & $17(73,9)$ & 0,029 \\
\hline Faringitis & $14(41,2)$ & $5(12,8)$ & 0,006 & $14(24,6)$ & $3(13)$ & NS \\
\hline Dolor abdominal & $1(2,9)$ & $4(10,3)$ & NS & $3(5,3)$ & $4(17,4)$ & NS \\
\hline Dolor torácico & $3(8,8)$ & $4(10,3)$ & NS & $0(0)$ & $3(13)$ & 0,022 \\
\hline Cefalea & $1(2,9)$ & $2(5,1)$ & NS & $0(0)$ & $3(13)$ & 0,022 \\
\hline Vómitos & $11(32,4)$ & $3(7,7)$ & 0,008 & $9(15,8)$ & $0(0)$ & 0,039 \\
\hline Otitis & $4(11,8)$ & $4(10,3)$ & NS & $8(14)$ & $2(8,7)$ & NS \\
\hline Afectación cutánea & $2(5,9)$ & $1(2,6)$ & NS & $4(7)$ & $0(0)$ & NS \\
\hline Dificultad respiratoria & $3(8,8)$ & $4(10,3)$ & NS & $18(31,6)$ & $4(17,4)$ & NS \\
\hline Diarrea & $4(11,8)$ & $3(7,7)$ & NS & $10(17,5)$ & $0(0)$ & 0,026 \\
\hline Anorexia & $4(8,8)$ & $4(10,3)$ & NS & $1(1,8)$ & $3(13)$ & NS \\
\hline AP patológica unilateral & $27(79,5)$ & $29(74,4)$ & NS & $33(57,9)$ & $15(65,2)$ & NS \\
\hline AP patológica bilateral & $4(11,8)$ & $7(17,9)$ & NS & $20(35,1)$ & $6(26,1)$ & NS \\
\hline AP normal & $3(8,8)$ & $3(7,7)$ & NS & $4(7)$ & $2(8,7)$ & NS \\
\hline Hipofonesis & $14(41,2)$ & $14(35,9)$ & NS & $13(22,8)$ & $7(30,4)$ & NS \\
\hline Crepitantes & $14(41,2)$ & $22(56,4)$ & NS & $25(43,9)$ & $13(56,5)$ & 0,024 \\
\hline Soplo tubárico & $0(0)$ & $3(7,7)$ & NS & $0(0)$ & $2(8,7)$ & NS \\
\hline Roncus & $4(11,8)$ & $1(2,6)$ & NS & $13(22,8)$ & $2(8,7)$ & NS \\
\hline Subcrepitantes & $4(11,8)$ & $6(15,4)$ & NS & $12(21,1)$ & $3(13)$ & NS \\
\hline Sibilantes & $2(5,9)$ & $2(5,1)$ & NS & $8(14)$ & $3(13)$ & NS \\
\hline Rx patológica unilateral & $27(79,4)$ & $20(84,6)$ & NS & $45(79)$ & $18(78,3)$ & NS \\
\hline Rx patológica bilateral & $7(20,6)$ & $6(15,4)$ & NS & $12(21,1)$ & $5(21,7)$ & NS \\
\hline Derrame pleural & $2(5,9)$ & $6(15,4)$ & NS & $2(3,5)$ & $1(4,3)$ & NS \\
\hline Adenovirus/Mycoplasma & $11(32,4)$ & $12(30,8)$ & NS & $11(19,3)$ & $12(52,2)$ & 0,003 \\
\hline Chlamydia & $3(8,8)$ & $8(20,5)$ & NS & $6(10,5)$ & $9(39,1)$ & 0,003 \\
\hline $\mathrm{PCR}>15 \mathrm{mg} / \mathrm{dl}$ & $15(44,1)$ & $4(10,3)$ & 0,001 & $14(25)$ & $3(13)$ & NS \\
\hline Leucocitos $>15.000 / \mathrm{ml}$ & $21(61,8)$ & $20(51,3)$ & NS & $36(63,2)$ & $10(4,5)$ & NS \\
\hline Neutrofilos $>60 \%$ & $28(82,3)$ & $33(84,6)$ & NS & $39(69,8)$ & $22(95,7)$ & 0,007 \\
\hline
\end{tabular}


material y métodos). De los casos de $M$. pneumoniae, 11 presentaban C. pneumoniae y 1 enterovirus. De los casos de adenovirus, 15 con C. pneumoniae, 2 con virus de Epstein Barr y 1 con virus respiratorio sincitial. En 8 casos se observaron coinfecciones entre $M$. pneumoniae, adenovirus y C. pneumoniae.

Entre los datos clínicos, radiológicos y analíticos no hubo diferencias estadísticamente significativas entre los casos de coinfecciones entre varios microorganismos, ni tampoco en la evolución.

\section{Análisis estadístico}

Entre el M. pneumoniae o adenovirus (tabla 1) hubo diferencias estadísticamente significativas en las siguientes variables: en la etiología por M. pneumoniae predominó la hipofonesis ( $p=$ $0,054)$ y neutrofilia $(p=0,044)$, mientras que en los adenovirus fue más frecuente la dificultad respiratoria ( $p=$ $0,005)$, la auscultación patológica bilateral $(p=0,012)$, los roncus $(p=0,029)$ y la fiebre más elevada $(p<0,001)$.

En cuanto a la edad superior o inferior a 5 años (tabla 2): en el caso de $M$. pneumoniae se encuentran diferencias estadísticamente significativas en la presencia de faringitis $(p=0,006)$, vómitos $(p=0,008)$, fiebre más elevada ( $p$ $=0,04)$ y PCR alta $(p=0,001)$, que pre- dominan en menores de 5 años. En caso de adenovirus estas diferencias fueron la presencia de tos $(p=0,029)$, vómitos $(p=0,039)$, diarrea $(p=0,026)$ y fiebre más elevada $(p=0,035)$, que predominan en menores de 5 años, al contrario que el dolor torácico ( $p=$ $0,022)$, la cefalea $(p=0,022)$, los crepitantes $(p=0,024)$, las coinfecciones con C. pneumoniae $(p=0,003)$ o $M$. pneumoniae $(p=0,003)$ y la neutrofilia ( $p=0,007)$ que predominaron en los mayores de 5 años.

\section{Discusión}

Este estudio retrospectivo demuestra la alta prevalencia del M. pneumoniae y adenovirus como responsables de neumonía en los niños, la elevada frecuencia de coinfecciones y la similitud clínica entre los menores y mayores de 5 años, así como entre ambos agentes etiológicos.

M. pneumoniae y adenovirus son etiologías frecuentes de neumonía en pediatría $^{1-7,9}$, y en nuestra casuística alcanzan una prevalencia del $11,2 \%$ y el $12,2 \%$, respectivamente, entre las neumonías diagnosticadas, semejante a los porcentajes reflejados en otras publica-

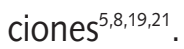

Destaca que el $53,4 \%$ de los casos de M. pneumoniae fueron diagnosticados 
entre los meses de marzo y julio, y el $47,5 \%$ de adenovirus durante el primer cuatrimestre del año, considerados en algunos estudios los meses más frecuentes ${ }^{5,6,9,13,19,22}$, aunque pueden ser identificados durante casi todo el año $0^{3,4,19,23}$.

La distribución anual refleja un aumento de la incidencia durante los años 2002 y 2004 de M. pneumoniae y en 2004 de adenovirus. Aumento que podría explicarse por haber coincidido con 2 brotes epidémicos locales y que concordaría con lo descrito epidemiológicamente $1-6,9,13-14$.

La presentación de M. pneumoniae en menores de 5 años suele estar infravalorada $^{5,79}$. Entre nuestros casos existe un alto porcentaje de infectados menores de 5 años, con una edad promedio por debajo de lo establecido clásicamente, coincidiendo con otros estudios recientes ${ }^{10,11,15,17}$. Este alto porcentaje puede ser debido a la escolarización precoz, que hace que los niños se expongan al agente a una edad anterior $y$, por lo tanto, induce una sensibilización que predispone a que nuevos contactos con el microorganismo cause infecciones más graves de forma más tempra$n^{5,9,12}$. Pero también podría existir otra causa: en nuestro estudio se utilizó la IgM para el diagnóstico y ésta no au- menta en las reinfecciones, sino que se produce una respuesta rápida de $\lg \mathrm{G} \mathrm{e}$ $\lg \mathrm{A}^{26}$, que en nuestros pacientes no se estudiaron, por lo que no se detectaron algunos casos que podrían haber ocurrido en escolares y adolescentes por reinfecciones. El paciente de menor edad tenía 12 meses, dato que coincide con otros estudios en los que se ve cómo en menores de 6 meses raramente se diagnostica, debido a que los anticuerpos maternos pueden ser todavía protectores $^{29}$.

En el caso de adenovirus, nuestros datos coinciden con los de la bibliografía al mostrar una prevalencia más elevada en menores de 5 años y especialmente por debajo de los $18 \mathrm{me}$ $\operatorname{ses}^{3,4,18-23}$.

Con estos resultados ambos microorganismos deben ser considerados agentes etiológicos de neumonía, tanto por encima como por debajo de los 5 años ${ }^{9,10,14}$, y tenerlos en cuenta a la hora de instaurar tratamiento empírico.

Un hecho constatado en nuestra casuística es que no existen grandes variaciones respecto a la clínica, radiología ni datos de laboratorio entre ambas infecciones, como tampoco datos relevantes que nos permitan distinguirlas de otros agentes etiológicos. Se ha descrito que el adenovirus se comporta como otros 
agentes virales, pero también puede mimetizar en sus manifestaciones clínicas, radiológicas y analíticas, a infecciones bacterianas, que motiva frecuente antibioterapia innecesaria e inefecti$\mathrm{va}^{4,19,23,24}$.

Clásicamente se considera la existencia de un patrón radiológico sugestivo de cada etiología, aunque no sean patognomónicos ${ }^{1,2,16}$. En el caso del $M$. pneumoniae se trataría de un patrón intersticial retículo-nodular parcheado (unilateral o bilateral), y el adenovirus presentaría hiperinsuflacion pulmonar, engrosamiento de la pared bronquial, bronconeumonía difusa y colapso lobar $^{19,24,25}$. Sin embargo, en la actualidad existe evidencia que sostiene que estas infecciones pueden adoptar cualquier patrón radiológico ${ }^{10,14,23,29,30}$, que hace también difícil diferenciar estos microorganismos entre ellos y con otros. Entre nuestros pacientes la radiografía tampoco aportó imágenes específicas y predominó la unilateralidad en ambas etiologías.

En el momento en que se establece el diagnóstico clínico y/o radiológico de neumonía, interesa realizar la presunción etiológica y no es fácil. Clásicamente, la forma de instauración, la exploración, el patrón radiológico y los reactantes de fase aguda, se considera- ba que podían ser determinantes. Pero artículos recientes sugieren que, en las neumonías comunitarias, los microorganismos considerados responsables de las neumonías atípicas pueden cursar con características similares a las infecciones neumocócicas, en especial los reactantes de fase aguda ${ }^{5,8-11,14,17,23,29,30}$, hecho que confirmamos en nuestro estudio, con predominio de leucocitosis, neutrofilia y aumento de PCR.

La única forma de establecer el diagnóstico etiológico de certeza es con pruebas serológicas específicas, cultivo o PCR, y generalmente el resultado tarda, sobre todo en Atención Primaria, que es donde con más frecuencia se presenta ${ }^{6,14,27,28}$. El diagnóstico etiológico rápido es importante y se debería implantar técnicas que lo permitan y ayuden a evitar el uso indiscriminado de antibióticos ${ }^{22}$. Para el diagnóstico en nuestro estudio no se realizó la PCR por no estar disponible en esos años en el laboratorio; se utilizó la IgM específica mediante la técnica de enzima inmunoensayo (hay que objetivar su incremento a los 7 días).

Con relativa frecuencia se describen manifestaciones extrarrespiratorias en ambas etiologías; en la bibliografía llegan al 30\% y coincide con lo encontrado entre nuestros casos $(34,6 \%)^{6,16,19,21,22}$. Sig- 
nos clínicos, como conjuntivitis o exantemas, que están comúnmente asociados con el adenovirus, fueron infrecuentes en nuestros pacientes.

El tratamiento con macrólidos de las neumonías por M. pneumoniae permite mejorar la morbilidad y acortar la duración de los síntomas, incluso si se empieza de forma tardía $2,9,10$. Sin tratamiento la duración clínica es de 3-4 semanas, con un curso autolimitado ${ }^{7,29}$. Hay autores que sugieren que el tratamiento adecuado mejora el curso de la enfermedad reactiva de las vías respiratorias, las pruebas de función pulmonar, disminuye la tasa de episodios de sibilantes recurrentes y otros síntomas respirato$\operatorname{rios}^{12,14}$. En la serie revisada, 91 de los 153 casos no empezaron con macrólidos y la evolución de la fase aguda fue correcta.

Hemos constatado entre los casos estudiados que tanto la neumonía por $M$. pneumoniae como por adenovirus no causa compromiso respiratorio grave, aunque se han descrito casos graves, alguno con desenlace fatal2,12,17,29.

No se pudo demostrar en nuestros casos las secuelas a largo plazo descritas en la bibliografía, sobre todo por adenovirus ${ }^{20,21,23}$, ya que no se realizó un seguimiento posterior.

Finalmente, es importante destacar el porcentaje de coinfecciones encontrado. Podría ser más elevado, ya que no se estudió sistemáticamente en todos los casos la presencia de virus respiratorios como rinovirus, metapneumovirus, bocavirus o influenza. Entre las coinfecciones demostradas no se observó diferencias en la evolución clínica, ni en otros datos recogidos, aunque algunos estudios han descrito cuadros clínicos más graves y una evolución más tórpida?

Sería interesante el seguimiento a lo largo del tiempo de los niños afectados por estos microorganismos, ya que se han detectado secuelas y alteración de la pruebas de función pulmo$\operatorname{nar}^{14,20,23,25}$.

\section{Bibliografía}

1. Brines J, Hernández R. Neumonías agudas en la infancia. En: Cruz Hernández M. Tratado de Pediatría. 9. ${ }^{a}$ ed. Madrid: Editorial Ergon; 2006. p. 1323-1339.
2. Dwight A. Infecciones por Mycoplasma. Mycoplasma pneumoniae. En: Nelson WE. Tratado de Pediatría. 16. ${ }^{a}$ ed. Mc Graw-Hill; 2001. p. 1004-5.

3. Tardío E, Sánchez E. Adenovirosis. En: Cruz Hernández M. Tratado de Pediatría. 9. ${ }^{a}$ ed. Madrid: Editorial Ergon; 2006. p. 475-477. 
4. McIntosh K. Adenovirus. En: Nelson WE. Tratado de Pediatría. 16. ${ }^{a}$ ed. Mc Graw-Hill; 2001. p. 1090-92.

5. Gómez Campderá JA, Rodríguez Fernández R, Navarro Gómez ML, González Sánchez MI, Megías Montijano A. Neumonía por "Mycoplasma": endemia frente a epidemia. Acta Pediatr Esp. 2006;64:536-44.

6. Sánchez Ruiz-Cabello J, Maldonado Espinosa MJ, Rubio Quevedo C, Rosales Zabel JM, Pereira Rodríguez MJ, Holgado Carballo MA. Neumonía por Mycoplasma pneumoniae en una zona básica de salud. An Esp Pediatr. 2001;55: 108-12.

7. Megías Montijano A, Gómez Campderá JA, Navarro Gómez ML, Urán Moreno M, González Sánchez MI, Rodríguez Fernández R. Coinfección por Chlamydia y Mycoplasma. Incidencia en nuestro medio. An Esp Pediatr. 2002;57:110-4.

8. Scheneeberger PM, Dorigo-Zetsman JW, van der Zee A, van Bon M, van Opstal JL. Diagnosis of atypical pathogens in patients hospitalized with community-adquired respiratory infection. Scan J Infect Dis. 2004;36:269-73.

9. Gómez Campderá JA, Rodríguez Fernández R, Megías Montijano A, González Sánchez MI, Navarro Gómez M, Ruiz Magro P. Neumonía por Mycoplasma pneumoniae en pacientes menores de 3 años. Acta Pediatr Esp. 2002;60: 343-7.

10. Principi N, Esposito S. Emerging role of Mycoplasma pneumoniae and Chlamydia pneumoniae in paediatric respiratory-tract infections. Lancet Infect Dis. 2001;1:334-44.

11. Esposito S, Bosis S, Cavagna R, Faelli N, Begliatti E, Marchisio P, et al. Characteristics of Streptococcus pneumoniae an Atypical Bacterial Infections in Children 2-5 years of Age with Community-Acquired Pneumonia. Clin Infect Dis. 2002;35:1345-52.
12. Rodríguez Fernández R, Gómez Campderá JA, Arana Amurrio I, Ruiz Magro P, Zapatero La Calle M, Casanova Morcillo A, y cols. Neumonía por Mycoplasma pneumoniae con complicaciones extrapulmonares en paciente pediátrico. Acta Pediatr Esp. 2002;60:410-4.

13. Gómez Campderá JA, Sanz López E, Dobón $P$, Serrano C, Navarro NL. Estudio de 6 años sobre neumonía por "Mycoplasma pneumoniae" en un hospital terciario pediátrico. Acta Pediatr Esp. 2007;65:570-6.

14. Principi N, Esposito S, Blasi F, Allegra L, Mowgli Stugy Group. Role of Mycoplasma pneumoniae and Chlamydia pneumoniae in Children with Community-Acquired Lower Respiratory Tract Infections. Clin Infect Dis. 2001;32:1281-9.

15. Ferrero FC, Ossorio MF, Eriksson PV, Duran AP. Mycoplasma pneumoniae en niños con neumonía. Arch Argent Pediatr. 2000;98:12-7.

16. Acosta Pascual D, Zamora Mantas D, López Parra MD, Riñones Mena E, Delgado Carrasco J. Infección por Mycoplasma pneumoniae. Acta Pediatr Esp. 2004;62:254-6.

17. Amantéa S, Manica AL, Leaes CG, Frey BN. Mycoplasma pneumoniae pneumonia: clinical and radiological features. J Pediatr (Rio J). 2000;76:315-22.

18. Bernaola G, Luque W. Fisiopatología de las Infecciones por Adenovirus. Paediatrica. 2001;4:41-7.

19. Reina J, Ferres F, Gutiérrez $O$, Ruiz de Gopegui $E$, González-Cárdenas M. Estudio de las características clínicas y epidemiológicas de las infecciones respiratorias por adenovirus en una población infantil (1997-2003). An Pediatr (Barc). 2004;61:137-42.

20. Pham T, Burchette J, Hale L. Fatal Disseminated Adenovirus Infections in Immunocompromised Patients. Am J Clin Pathol. 2003;120:575-83. 
21. Farng $K$, Wu $K$, Lee $Y$, Lin $Y$, Hwang $B$. Comparison of clinical characteristics of adenovirus and non-adenovirus pneumonia in children. J Microbiol Immunol Infect. 2002;35:37-41.

22. Rocholl C, Gerber K, Daly J, Pavia A, Byington C. Adenoviral Infections in Children: The Impact of Rapid Diagnosis. Pediatrics. 2004;113;e51-e56.

23. Chuang Yu-Yu, Chiu Cheng-Hsun, Wong Kin-Sun, Huang Joyce-Guei, Huang Yhu-Chering, Chang Luan-Yi, et al. Severe adenovirus infection in children. J Microbiol Immunol Infect. 2003;36:37-40.

24. Han B, Son J, Yoon H, Lee S. Epidemic Adenoviral Lower Respiratory Tract Infection in Pediatric Patients: Radiographic and Clinical Characteristics. Am J Roentgenol. 1998;170: 1077-80.

25. González R. Adenovirus: Neumonía, enfermedad pulmonar crónica y asma. Rev Med Clin Condes. 2007:18:165-8.

26. Matas L, Molinos S, Fernández G, Gonzá- lez V, Ausina V. Diagnóstico serológico de las infecciones por Mycoplasma pneumoniae. Enferm Infecc Microbiol Clin. 2006;24 (Supl 1):19-23.

27. Morozumi J, Hasegawa K, Chiba N, Iwata $\mathrm{S}$, Kawamura $\mathrm{N}$, Kuroki $\mathrm{H}$, et al. Application of PCR for Mycoplasma pneumoniae detection in children with community-acquired pneumonia. J Infect Chemother. 2004;10:274-9.

28. Morozumi $M$, Ito A, Muramaya SY, Hasegawa $K$, Kobayashi $R$, Iwata $S$, et al. Assessment of real-time PCR for diagnosis of Mycoplasma pneumoniae pneumonia in pediatric patients. Can J Microbiol. 2006;52:125-9.

29. Somer A, Salman N, Yalçin I, Agaçfidan A. Role of Mycoplasma pneumoniae and Chlamydia pneumoniae in Children with CommunityAcquired Pneumonia in Istanbul, Turkey. J Trop Pediatr. 2006;52:173-8.

30. Hsieh SC, Kuo YT, Chern MS, Chen CY, Chan WP, Yu C. Mycoplasma pneumonia: clinical and radiographic features in 39 children. Pediatr Int. 2007;49:363-7. 